\title{
Tools to improve forecasting and control of the electricity consumption in hotels
}

\author{
Juan José Cabello Eras, Vladimir Sousa Santos, Alexis Sagastume Gutierrez, \\ Mario Alvarez Guerra Plasencia, Dries Haeseldonckx, Carlo Vandecasteele.
}

\begin{abstract}
Hotels are among the most energy intensive tourism facilities. To monitor and control the monthly and yearly energy consumption in hotels, different indicators have been proposed. These indicators, developed on yearly or annual basis, do not permit rapid detection and mitigation of malpractices and overconsumptions in hotel facilities. Moreover, these indicators do not consider the influence of physical parameters such as outdoor temperature, or, when they do, rather complex coefficients are used, precluding implementation in hotel facilities. This study discusses the use of Energy Performance Indicators to assess and control the electricity consumption in hotels. To this end a new indicator considering the outdoor temperature is introduced. Based on this indicator daily control graphs are developed, allowing a more rapid detection of overconsumptions and malpractices towards a higher electricity efficiency. One advantage of this approach is that no investments are required to implement it. The tools were implemented in two Cuban hotels of different characteristics, where reductions of the electricity consumption in 2014 compared to 2013 of 10 and $11 \%$, were achieved.
\end{abstract}

\section{Keywords}

Energy efficiency, Energy management, Hotels energy efficiency 